\title{
Clinical appraisal of abiraterone in the treatment of metastatic prostatic cancer: patient considerations, novel opportunities, and future directions
}

\author{
This article was published in the following Dove Press journal: \\ OncoTargets and Therapy \\ 31 December 2012 \\ Number of times this article has been viewed
}

\author{
Diego J Bedoya' \\ Nicholas Mitsiades ${ }^{2,3}$ \\ 'Clearview Cancer Institute, \\ Huntsville, AL, USA; ${ }^{2}$ Department of \\ Medicine, ${ }^{3}$ Department of Molecular \\ and Cellular Biology, Baylor College \\ of Medicine, Houston, TX, USA
}

\begin{abstract}
While androgen-deprivation therapy can induce dramatic clinical responses in advanced and metastatic prostate cancer, refractory disease (castration-resistant prostate cancer [CRPC]) eventually emerges. In recent years, several studies have demonstrated the importance of residual intratumoral androgens in maintaining androgen receptor (AR) transcriptional activity in CRPC. The cytochrome P450 enzyme CYP17 is an obligatory step in androgen synthesis, and therefore a critical therapeutic target in CRPC. Abiraterone acetate is a selective, irreversible inhibitor of CYP17 and can suppress adrenal synthesis of androgen precursors, and possibly in situ steroidogenesis in the tumor microenvironment. In a phase III multicenter study, abiraterone in combination with prednisone improved median overall survival of men with docetaxelrefractory CRPC by 3.9 months compared to placebo plus prednisone, and also resulted in higher objective prostate-specific antigen and radiographic response rates. The study led to the FDA approval in April 2011 of abiraterone for treatment of chemotherapy-refractory CRPC patients, validating steroidogenesis and the AR axis in general as therapeutic targets in CRPC. The FDA indication for abiraterone was expanded to all CRPCs in December 2012, while evaluation in even earlier disease states is ongoing. We propose a comprehensive AR axis-targeting approach via simultaneous, frontline enzymatic blockade of several steroidogenic enzymes (eg, CYP17 and AKR1C3) in combination with gonadotropin-releasing hormone analogs and potent, second-generation AR antagonists (eg, enzalutamide) in order to improve outcomes in patients with prostate cancer.
\end{abstract}

Keywords: androgen synthesis, testosterone, dihydrotestosterone, CYP17, AKR1C3, MDV3100 (enzalutamide)

\section{Introduction}

Prostate cancer is the most common noncutaneous cancer diagnosed among US men, representing approximately 240,000 new diagnoses annually. Although many patients are diagnosed early and potentially cured with local therapy, a significant number of patients are still diagnosed with or eventually develop metastatic disease, which is currently incurable. For this reason, prostate cancer - estimated to be responsible for approximately 28,000 deaths in 2012 - is still the second-leading cause of cancer deaths in men. ${ }^{1}$ Despite this, the clinical management of advanced prostate cancer remained fairly stagnant for many years. Indeed, over the past seven decades, ${ }^{2}$ few therapeutic options beyond androgen-deprivation therapy (ADT) via gonadal suppression (orchiectomy or gonadotropin-releasing hormone [GnRH] analogs) were 
available for men who were diagnosed with or developed advanced or metastatic prostate adenocarcinoma after local treatment. ${ }^{3}$ Unfortunately, clinical resistance to ADT eventually emerges, usually manifested as tumor regrowth associated with an increase in the serum prostate-specific antigen (PSA) levels, and this phenomenon is usually associated with fatal outcomes. ${ }^{4}$ Further attempts at manipulating the androgen axis with ketoconazole (an antifungal agent with activity as an androgen synthesis inhibitor) or with firstgeneration androgen receptor (AR) antagonists (flutamide, bicalutamide, nilutamide) are frequently successful at reducing PSA levels, but unfortunately these responses are short-lived. Moreover, ketoconazole is poorly tolerated at the doses required to inhibit androgen synthesis. ${ }^{5}$ In this clinical setting, the disease was traditionally considered "hormone-refractory" or "androgen-independent," and cytotoxic chemotherapy has been used, despite only modest efficacy and limited choices of active agents. ${ }^{6}$ In fact, it was only in 2004 that a cytotoxic chemotherapeutic agent (docetaxel) demonstrated for the first time evidence of a statistically significant overall survival benefit, ${ }^{7}$ and it was only recently that a second-line cytotoxic chemotherapeutic agent (cabazitaxel) was documented to provide overall survival benefit. ${ }^{8-10}$

It is now becoming clearer that prostate cancer growth can still remain dependent on androgen supply and sensitive to hormonal manipulation, even in the setting of disease previously called hormone-refractory or androgen-independent, and that those terms are grossly inaccurate. Newer evidence shows that even when measured serum testosterone levels are in the castrate range $(<50 \mathrm{ng} / \mathrm{dL})$, the $\mathrm{AR}$ axis in the prostate cancer cells can remain active and still play a significant role in their proliferation..$^{3,4,6,11-13}$ Clinically, the increase in serum PSA (whose gene expression is critically dependent on AR activity) seen at progression after ADT, and its subsequent decline with second-line hormonal therapies, demonstrate that the AR pathway remains active ${ }^{14}$ regardless of the circulating levels of testosterone. Other AR target genes, including TMPRSS2 and KLK2, show similar expression patterns. ${ }^{13}$ Hence, the more appropriate term "castration-resistant prostate cancer" (CRPC) should be used instead. ${ }^{3}$ Furthermore, the AR signaling axis is hypersensitized to the residual levels of androgens arising from extragonadal sources. Proof of principle for this concept was provided with the introduction of abiraterone acetate, a potent CYP17 inhibitor. This highlights the importance of understanding the steroidogenic pathway(s) that operate in prostate cancer.

\section{Brief overview of androgen synthetic pathways}

Cholesterol is the precursor for synthesis of all steroids ${ }^{15}$ including androgens (Figure 1). Androgen synthesis requires two key cytochrome P450 enzymes (CYP11 and CYP17) and two hydroxysteroid dehydrogenases (3 $\beta$-HSD and $17 \beta$-HSD). ${ }^{16,17}$ The expression of CYP11, CYP17, and 3 $\beta$-HSD in steroidogenic tissues is regulated by the transcription factor steroidogenic factor-1 (SF-1 or NR5A1), which binds to and activates the corresponding gene promoters. ${ }^{18}$ In fact, SF-1 inactivation by germ-line mutations in humans or by genetic manipulation in mice leads to gonadal and adrenal failure. ${ }^{19}$ In the adrenal cortex (zona reticularis and zona fasciculata), adrenocorticotropic hormone activates SF-1 via the cyclic adenosine monophosphate/ protein kinase A pathway. ${ }^{20,21}$

Androstenedione, dehydroepiandrosterone (DHEA), and DHEA sulfate, the main products of the androgen synthesis pathway in the human adrenal gland, are only weak AR agonists, but can become a critical source of residual AR stimulation in prostate cancer patients treated with ADT. Conversion of these weaker androgens into testosterone requires a family of enzymes with $17 \beta$-HSD activity. In prostate tissue (including adenocarcinoma), this is mediated by HSD17B5 (also known as AKR1C3). ${ }^{22}$

In target tissues, testosterone is reduced to dihydrotestosterone (DHT) via $5 \alpha$-reductases. As DHT has a higher affinity than testosterone for AR (five- to tenfold), ${ }^{23,24}$ the expression of $5 \alpha$-reductases acts as a mechanism of in situ amplification of the androgen signal in different target tissues.

\section{Development of castration resistance in prostate cancer and persistence of AR signaling}

GnRH agonists, the mainstay of treatment for advanced prostate cancer, suppress circulating testosterone levels usually to below $50 \mathrm{ng} / \mathrm{dL}$ and were thought, based on in vitro and animal experiments, to be capable of inducing apoptosis of prostate cancer cells. It is now clear, however, that ADT causes only a minor wave of initial apoptosis, followed by mostly growth arrest of prostate cancer cells..$^{25} \mathrm{In}$ fact, these cells have the ability to adapt to these castrate levels of circulating testosterone and eventually restart to proliferate. ${ }^{26}$ Furthermore, recent in vitro data demonstrated that a subset of the prostate cancer cells that survive after castration exhibit increased expression of stem cell markers and are subsequently able to repopulate the tumor, likely through adaptive changes in the AR axis. ${ }^{27}$ 


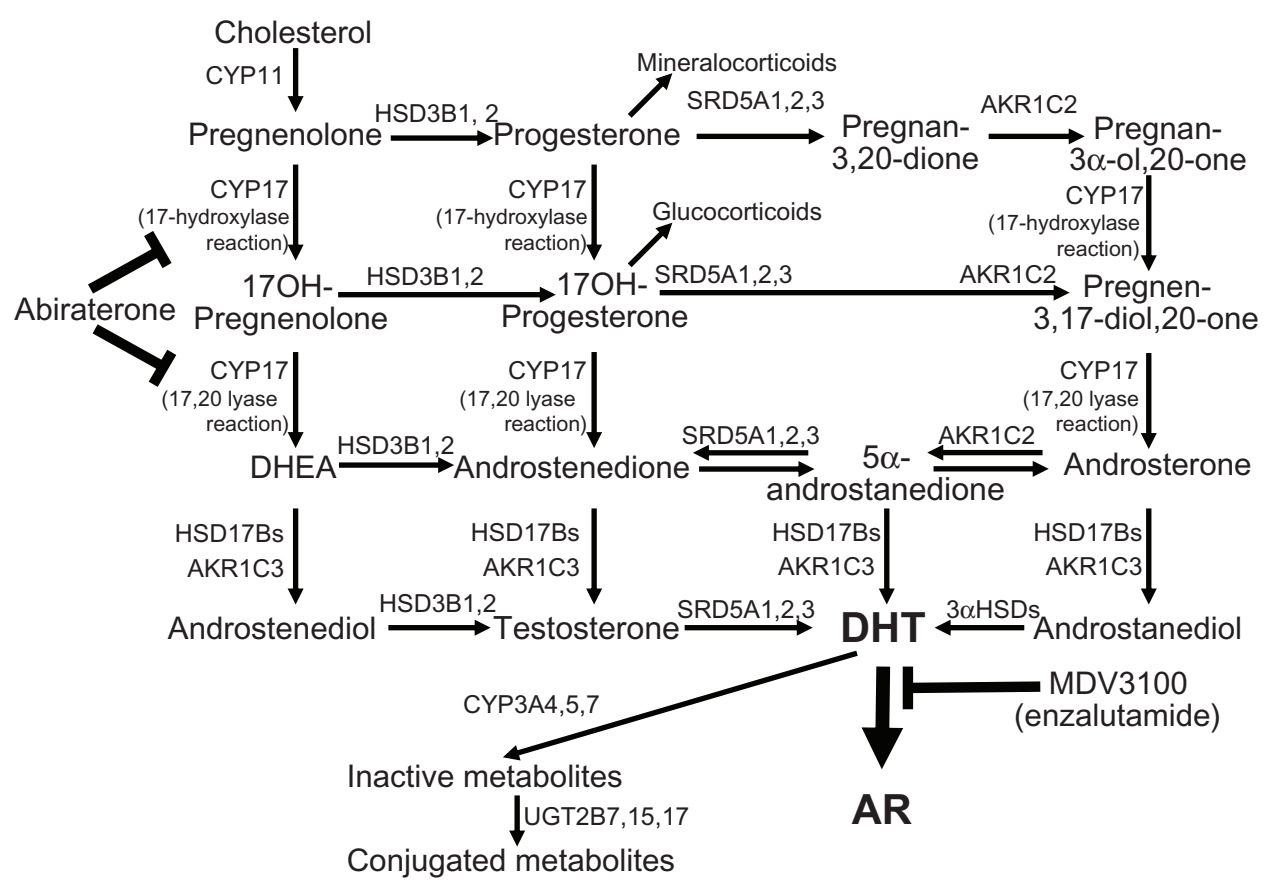

Figure I Enzymatic pathways of androgen synthesis, and target sites of abiraterone (CYPI7 inhibitor) and enzalutamide (MDV3 I00, antagonist of androgen receptor [AR]) action.

Human AR is encoded by a single gene on chromosome $\mathrm{X}(\mathrm{Xq} 11-12),{ }^{12}$ and when unstimulated is predominantly located in the cytoplasm. After ligand binding, the AR translocates to the nucleus, ${ }^{3}$ where it regulates transcription of target genes that modulate differentiation and growth of prostate epithelial cells. AR binds to androgen-response elements throughout the genome and subsequently recruits coregulators (coactivators and/or corepressors) that in turn recruit and regulate the core transcriptional complex. Importantly, these coregulators can be modified in a posttranslational fashion, allowing for the AR signal to "cross-talk" with other signaling pathways, including Src, Akt, human epidermal growth factor receptor 2, insulin-like growth factor 1 receptor, and interleukin- $6,{ }^{12,28-35}$ as well as potentially amplify the AR signal under castration conditions.

The persistence of AR signaling in CRPC is frequently manifested by the reexpression of PSA. Several mechanisms have been proposed to explain the persistence of AR transcriptional activity in these diverse and heterogeneous tumors, with increasing evidence that they are not mutually

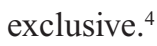

For example, constitutively active AR variants have been described that lack the ligand-binding domain (LBD) and can function in a ligand-independent fashion. Such variants can originate from alternative splicing of the AR transcript. ${ }^{36,37}$ Additional AR truncated variants have been described as products of proteolytic cleavage of full-length AR to remove the carboxy-terminal LBD, in order to generate a constitutively active transcription factor. ${ }^{38,39}$

Also, AR mRNA and protein overexpression, frequently caused by $A R$ gene amplification, has been reported in a large subset of CRPCs, ${ }^{6,40-42}$ leading to an increased sensitivity to low androgen levels. ${ }^{43}$ Similarly, this increased sensitivity can be seen in association with gain-of-function mutations in the AR LBD, ${ }^{4,6,41}$ which can also lead to activation of AR by noncanonical ligands, including estrogen, progesterone, or mineralocorticoids. Both AR overexpression and gain-offunction mutations, as well as changes in the coactivators/ corepressors ratio, ${ }^{6}$ can underlie the antagonist-to-agonist conversion of first-generation antiandrogens (flutamide, bicalutamide, and cyproterone acetate). ${ }^{3,44}$ This phenomenon is responsible for the "antiandrogen withdrawal" responses, ${ }^{45}$ ie, clinical responses (decline in PSA) seen in $~ 20 \%-25 \%$ of CRPC patients upon discontinuation of first-generation antiandrogens. It could also provide an explanation for the lack of significant additional survival benefit when these medications are used up front in conjunction with ADT as "combined androgen blockade" (CAB) ${ }^{46}$

Most important is, however, the fact that while GnRH agonists are very effective in achieving castrate levels of circulating testosterone, the production of androgen precursors in the adrenal glands persists. As a result, the serum levels of androstenedione, DHEA, and DHEA sulfate are only mildly suppressed after $\mathrm{ADT},{ }^{47,48}$ and remain more than adequate 
to serve as precursors for intratumoral conversion to testosterone and $\mathrm{DHT}^{49}$ (of note, in healthy, hormone-naive adult males, the circulating DHEA sulfate concentration is up to 500 times higher than that of testosterone). Treatment with GnRH agonists usually suppresses circulating testosterone and DHT by more than $90 \%$, but the intraprostatic concentrations of these androgens decrease by only $60 \%-80 \%,{ }^{50,51}$ which highlights the importance of the extragonadal sources of androgen. Furthermore, the intratumoral concentration of testosterone in the metastatic tissue of CRPC patients (ie, with castrate levels of circulating testosterone) has been found to be up to four times higher than its concentration in primary prostate tissue from untreated, hormone-naive patients, ${ }^{52}$ and in any case more than sufficient to stimulate AR-dependent gene expression. ${ }^{26,53,54}$ Taken together, these findings suggest that prostate cancer cells, in a castrate environment, are able to mount an adaptive response that allows using adrenal precursors to synthesize testosterone and DHT. In fact, some of the enzymes responsible for this conversion (SRD5A1, AKR1C3, CYP17A1, HSD3B1, HSD3B2, HSD17B3, and CYP19A1) have been found to be upregulated in different studies, ${ }^{42,52,55-57}$ although some variability between these studies is to be noted. The latter reflects the marked heterogeneity existing between these tumors ${ }^{42}$ and underscores the importance of this steroidogenic pathway as a whole. Moreover, inactivation of androgens in the prostate adenocarcinoma microenvironment is also believed to be aberrant, due to decreased expression of DHT-inactivating enzymes. ${ }^{42,58}$

Less well established is the concept of de novo testosterone synthesis directly from cholesterol in prostate cancer cells, ${ }^{49}$ as conflicting data are available to date. Some investigators have reported that CYP17 is upregulated in prostate cancer cells when exposed to androgen-deprivation therapy, ${ }^{52}$ suggesting that prostate carcinomas may possess the complete enzymatic machinery necessary to convert cholesterol to testosterone in a cell-autonomous fashion. Others have failed to obtain the same results, and have concluded that the levels of CYP17 in prostate cancer cells are not sufficient by themselves to promote local synthesis of testosterone, therefore relying on adrenal precursors to this end. ${ }^{57}$ Our own findings suggest that CYP17 is overexpressed in a small but distinct subset of prostate carcinomas. ${ }^{42}$ These tumors are probably too few for this effect to reach statistical significance when considered as average CYP17 expression across all prostate cancers, thus explaining the negative studies mentioned above. ${ }^{57}$ However, these CYP17 expression outliers (overexpressors) may constitute a distinct group of prostate carcinomas that can accomplish all the steps of androgen synthesis using cholesterol as a precursor (thus being completely independent of adrenal contribution of steroids). Such observations may have treatment implications for this subset of patients.

In any case, prostate cancer cells remain dependent on the androgen supply for their survival, and are far from being "androgen-independent" or "hormone-refractory." The response to second-line hormonal manipulations, with agents such as ketoconazole (off-label use) or more recently abiraterone is a proof of principle for this. In fact, patients with CRPC who have higher androgen levels at baseline are more likely to respond to the second-line hormonal therapies, ${ }^{59}$ and it has been suggested that measuring circulating adrenal androgen levels may predict response and guide treatment in these patients. ${ }^{60}$

\section{Development of abiraterone}

Ketoconazole, an imidazole derivative, has inhibitory activity on several enzymes in the androgen synthesis pathway. However, this activity is relatively weak and unselective. ${ }^{61}$ Furthermore, it is usually tolerated poorly at the recommended dose. The observations that nonsteroidal 3-pyridil esters have improved selectivity for the inhibition of CYP $17^{62}$ led to the development of abiraterone. ${ }^{63}$ Structurally, abiraterone is closely related to pregnenolone, and pharmacokinetic studies in mouse models showed that it achieves several times more potent inhibition of the hydroxylase/lyase CYP17 activity (Figure 1) than ketoconazole. In its unconjugated form, abiraterone is quickly hydrolyzed by esterases, and hence a more stable prodrug was developed - abiraterone acetate. ${ }^{64}$ Initial phase I studies showed that abiraterone was not only effective in further suppressing testosterone levels in castrated human individuals but was also well tolerated, ${ }^{65}$ without any of the significant toxicities seen with ketoconazole.

A second open-label, dose-escalation, single-center phase I study confirmed PSA decline of more than 50\% in $57 \%$ of the cohort when continued administration of abiraterone was given. A dose of $1000 \mathrm{mg}$ daily was recommended for phase II trials. ${ }^{66}$ The extension phase I/II study of 42 patients receiving this recommended dose resulted in a PSA decline of greater than $50 \%$ in $67 \%$ of patients. More importantly, a secondary decline of more than $50 \%$ in PSA levels was observed when dexamethasone was added, regardless of prior dexamethasone exposure. The mechanism proposed to explain this phenomenon is as follows: CYP17 catalyzes two enzymatic reactions (17-hydroxylase and 17,20 lyase) and is necessary for both glucocorticoid and androgen synthesis. Abiraterone completely inhibits both 
reactions and suppresses both glucocorticoid and androgen synthesis. In the absence of glucocorticoid supplementation, abiraterone leads to compensatory elevation of serum adrenocorticotropic hormone levels and increased adrenal conversion of cholesterol to pregnenolone and progesterone (which does not require CYP17). The latter can function as an AR agonist by itself, and can also be converted to $3 \alpha 5 \alpha$ 17-hydroxy-pregnanolone, and eventually to DHT via the backdoor pathway. ${ }^{67}$ Moreover, because mineralocorticoids are synthesized from progesterone (Figure 1), their production is spared when CYP17 is inhibited. As a result, accumulation of progesterone promotes mineralocorticoid excess and the development of the corresponding syndrome (fluid retention, edema, hypertension, and hypokalemia) that occurs in patients treated with abiraterone in the absence of corticosteroid replacement therapy ${ }^{67}$ Therefore, the use of low-dose (replacement) corticosteroids is recommended in combination with abiraterone, to suppress the accumulation of pregnenolone, progesterone, and mineralocorticoids, in order to (1) decrease the risk of mineralocorticoid side effects and (2) enhance its anticancer activity. ${ }^{5,67}$ This combination of abiraterone with replacement-dose glucocorticoids (prednisone) was used in another phase II study including 58 patients with metastatic CRPC who had previously progressed after docetaxel therapy. In this study, a decline in PSA by more than $50 \%$ was observed in $36 \%$ of the patients, with a trend towards better response in those who were ketoconazole-naive ${ }^{67,68}$ However, a meaningful response was still seen even in patients who had previously received ketoconazole, a finding that has been corroborated by a separate phase I trial. ${ }^{69}$

These preliminary findings were confirmed by the landmark phase III multicenter study by de Bono and colleagues, ${ }^{70}$ which compared the use of abiraterone in combination with prednisone vs placebo plus prednisone in the post-docetaxel setting. In this study, median overall survival was 14.8 months in those patients treated with abiraterone plus prednisone, compared to 10.9 months in those receiving placebo plus prednisone, representing a 35\% reduction in risk of death. Higher objective PSA and radiographic responses were also evident, as well as a longer time to progression based on these parameters. The study led to the FDA approval in April 2011 of abiraterone acetate for use in chemotherapy-refractory CRPC.

\section{Ongoing clinical trials involving earlier clinical states}

Originally, abiraterone was approved for use only in chemotherapy (docetaxel)-refractory CRPC. However, the better understanding of its mechanism of action and its relatively well-tolerated adverse event profile make the possibility of its use before chemotherapy very attractive. Ongoing trials are addressing this question. In a recently presented abstract, Ryan and colleagues ${ }^{71}$ showed interim-analysis data of the COUAA-302 study, evaluating the role of abiraterone in combination with prednisone in patients with metastatic CRPC who are chemotherapy-naive. This multicenter study included 1088 patients and showed improvement in the coprimary (overall survival, radiographic progression-free survival) and secondary end points. Based on this data, the Independent Data Monitoring Committee recommended the study to be unblinded and allowed crossover. Among the secondary end points, the use of abiraterone delayed time to chemotherapy initiation from 16.8 months to 25.2 months when compared to prednisone alone. On December 10, 2012, the US Food and Drug Administration approved an expanded indication for abiraterone acetate in combination with prednisone for the treatment of all patients with metastatic CRPC, thus including chemotherapy-naive CRPC.

As stated above, the degree of apoptosis encountered in prostate cancer cells after androgen depletion obtained with $\mathrm{GnRH}$ agonist monotherapy is inadequate to promote significant pathological responses. Hence, there is increasing interest in a possible role of abiraterone in combination regimens in the neoadjuvant setting. In this regard, a recent study enrolled 58 men with localized high-risk prostate cancer to receive leuprolide alone or in combination with abiraterone for the first 12 weeks followed by combination of leuprolide plus abiraterone on both arms for another 12 weeks prior to radical prostatectomy. ${ }^{72}$ There was a trend for a higher percentage of patients with complete or nearcomplete pathological response after receiving abiraterone for 24 weeks vs 12 weeks prior to prostatectomy (34\% vs $15 \%)$ that did not reach statistical significance $(P=0.0894)$. Another study of 37 patients receiving GnRH agonist plus abiraterone versus GnRH agonist for 12 weeks resulted in trends towards higher rates of pathological near-complete cytoreduction (24\% vs $8 \%$ ) and tumor downstaging (lymphnode infiltration was $28 \%$ vs $50 \%$ ), in those patients receiving abiraterone,$^{73}$ although again the $P$-values did not reach statistical significance. There are additional ongoing clinical trials exploring whether more profound androgen depletion in the tumor microenvironment would be capable of inducing clinically significant cancer cell apoptosis, tumor downstaging, and possibly improving long-term outcomes.

\section{Adverse events of abiraterone}

Unlike ketoconazole, abiraterone is generally a well-tolerated medication. In fact, in the phase III registration trial that led 
to its approval, the incidence of adverse events leading to discontinuation of treatment was not different in the group receiving abiraterone compared to those receiving placebo. Most of the side effects related to abiraterone use are secondary to mineralocorticoid excess, and include fluid retention, edema, hypertension, and hypokalemia, which are usually minimized by the concurrent administration of low-dose glucocorticoids (prednisone). Additionally, frequent monitoring of aminotransferase levels is recommended during the first few weeks of treatment, because some grade 4 elevations were observed, requiring temporary discontinuation of treatment. However, elevation of aminotransferase levels is usually reversible, and abiraterone can be safely reintroduced after dose reduction. ${ }^{70}$

\section{Other CYP I 7 inhibitors in clinical development}

As previously explained, CYP17 catalyzes two enzymatic steps (17-hydroxylase and 17,20 lyase), both of which are inhibited by abiraterone (Figure 1). Of these, the 17-hydroxylase activity is required for both androgen and glucocorticoid synthesis, while the 17,20 lyase activity is only required for androgen synthesis. ${ }^{41}$ Therefore, by blocking both steps, abiraterone requires concomitant glucocorticoid supplementation in order to avoid the side effects related to mineralocorticoid excess. A more selective inhibition of the 17,20 lyase activity would theoretically obviate this requirement. TAK-700 (orteronel) was designed to achieve this. A recent phase I study showed no added adverse effects of orteronel at a dose of $400 \mathrm{mg}$ twice a day when used concomitantly with docetaxel and prednisone. ${ }^{74}$ A multicenter clinical phase III trial using orteronel at this recommended dose plus prednisone in patients that progressed after docetaxel therapy is currently ongoing, with plans to recruit 1083 patients. Additionally, the same regimen is being evaluated in chemotherapy-naive patients. ${ }^{75}$ It is unclear whether the specificity of orteronel for the 17,20 lyase activity will be maintained at the higher dose required to obtain clinical responses (and as noted above, prednisone has already been added to these clinical trials anyway). Similarly, galeterone (TOK-001 or VN/124-1), a CYP17 inhibitor and AR antagonist, is in clinical development. ${ }^{3}$

\section{Possible mechanisms of resistance to abiraterone}

Despite the clinical benefits obtained with abiraterone acetate in CRPC, and the encouraging results seen in early clinical trials of orteronel, disease progression eventually will occur. Prostate cancer is a markedly heterogeneous disease, with potential for multiple mechanisms of resistance to castration (see "Development of castration resistance in prostate cancer and persistence of AR signaling"). The expression of AR variants, which lack the LBD and are constitutively active in a ligand-independent manner, increases acutely after androgen ablation, and conversely is suppressed by androgen treatment. ${ }^{76,77}$ Preclinical data suggest that abiraterone treatment upregulates the expression of AR (both full-length and truncated, constitutively active variant), thus proposing one potential mechanism that may explain resistance to abiraterone. ${ }^{78}$ Other proposed mechanisms of resistance to abiraterone are (1) upregulation of steroidogenic enzyme expression, including CYP17A1 (abiraterone's own target), ${ }^{78,79}$ and (2) accumulation of intratumoral pregnenolone/progesterone levels (that are synthesized upstream of CYP17) and can activate AR, in particular in the presence of certain LBD AR mutations ${ }^{79}$ or through conversion to $3 \alpha 5 \alpha-17$-hydroxypregnanolone and eventually to $5 \alpha$-dihydrotestosterone via the backdoor pathway. ${ }^{67}$ These putative mechanisms of resistance to abiraterone (or other CYP17 inhibitors) remain to be confirmed in clinical specimens of abiraterone-refractory CRPC tumors. In any case, however, these mechanisms highlight the importance of residual androgen metabolism in the presence of abiraterone, thus raising the possibility that resistance to abiraterone can potentially be overcome by using higher doses of abiraterone or additional inhibitors of other steroidogenic enzymes or by combination with potent AR antagonists, such as enzalutamide (MDV3100). ${ }^{78}$

\section{Enzalutamide (MDV3 I 00), a next- generation antiandrogen with clinical activity in CRPC}

In an example of rational compound design, a chemical library of AR ligands was created by using data from a cocrystal structure of bicalutamide bound with mutant AR. This library was screened for AR antagonistic activity, and a candidate compound, MDV3100 (enzalutamide), was selected for further testing. ${ }^{40}$ Enzalutamide has high affinity for AR, but unlike the first-generation antiandrogens (eg, bicalutamide), an antagonist-to-agonist conversion has not been observed so far. It has been reported that contrary to first-generation antiandrogens, enzalutamide does not promote AR nuclear translocation and DNA binding, hence providing an explanation for its pure antagonist nature. ${ }^{40}$ Phase I/II testing suggested that enzalutamide 
has clinical activity in CRPC, with relatively few side effects. ${ }^{14}$ In a phase III, double-blind, placebo-controlled trial, 1199 men with chemotherapy-refractory CRPC were randomly assigned in a 2:1 ratio to receive oral enzalutamide (160 mg daily) or placebo. At the time of a planned interim analysis, the median overall survival was 18.4 months in the enzalutamide group versus 13.6 months in the placebo group (hazard ratio for death in the enzalutamide group, 0.63 ; 95\% confidence interval $0.53-0.75$; $P<0.001)$. Enzalutamide was also superior to placebo with regard to the proportion of patients with PSA reduction by $\geq 50 \%$, soft-tissue response rate, time to PSA progression, radiographic progression-free survival, and time to first skeletal-related event. ${ }^{80}$ Based on these results, the study was unblinded and enzalutamide was approved on August 31, 2012 by the US Food and Drug Administration for the treatment of patients with metastatic CRPC who have previously received docetaxel.

\section{Choice of agent for docetaxel- refractory, castration-resistant prostate cancer}

Within a course of less than 2.5 years, four new therapeutic modalities became available to patients with castrationresistant prostate cancer in the post-docetaxel setting: the taxane cabazitaxel (Jevtana), the immunotherapeutic sipuleucel-T (Provenge), the CYP17 inhibitor abiraterone acetate (Zytiga), and the second-generation AR antagonist enzalutamide (Xtandi). ${ }^{9,10}$ At this moment, no data are available to guide oncologists and patients in their choice between these agents. In particular, no direct clinical comparison between these agents is available (in their corresponding registration trials, cabazitaxel was compared to mitoxantrone, while the other three were each compared to placebo). Furthermore, no biomarkers are available to help predict sensitivity to any of these agents, thus further complicating clinical decision-making. It is reasonable to anticipate that the nonchemotherapy approaches will be favored (by both patients and physicians) to be used prior to cabazitaxel (mainly due to the significant toxicity of the latter). ${ }^{9,10}$ As none of these approaches is curative, we anticipate that all patients will be eventually treated sequentially with all these agents. Nevertheless, it is unknown whether there is any cross-resistance between these agents (particularly important regarding the choice between abiraterone and enzalutamide, as both drugs target the AR axis). Therefore, the exact best sequence of using these agents remains undefined at this point.

\section{Combinations of novel agents}

Perhaps more important than the definition of the best sequence of using these novel agents individually will be their use in combination, especially in early disease states (eg, in neoadjuvant therapy and in early metastatic disease). It is reasonable to anticipate that a comprehensive AR axistargeting approach via simultaneous, frontline enzymatic blockade of steroidogenesis (ie, via abiraterone or other emerging steroidogenesis inhibitors), in combination with GnRH analogs and novel potent AR antagonists (ie, enzalutamide), would achieve deeper AR axis inhibition. Such a powerful combination strategy could replace the current prostate cancer treatment paradigm of sequentially adding agents at the time of disease progression. ${ }^{42}$ Clinical testing of the abiraterone plus enzalutamide combination has already begun (ClinicalTrials.gov identifier: NCT01650194). As both agents are very well tolerated individually, with minimal overlapping toxicity, their combination is expected to be well tolerated as well.

\section{Conclusion}

Abiraterone acetate is the first of a group of rationally targeted agents to become available for the management of castrateresistant prostate cancer. We can finally say that after 70 years of relatively few developments, the clinical management of prostate cancer is now enriched with several treatment options. The next challenge is to determine the best timing and sequence in which these drugs should be used. The use of abiraterone in combination with $\mathrm{GnRH}$ analogs and $\mathrm{AR}$ antagonists (eg, enzalutamide) up front could potentially induce higher degrees of apoptosis by means of a more potent and complete AR axis inhibition. This could result in further improvements in overall survival and progression-free survival in patients with prostate cancer, by delaying the emergence of resistance to castration. Also, the rate of pathologic complete responses seen when abiraterone is included in the neoadjuvant management of high-risk localized prostate cancer is promising, as it may form the basis of combination regimens that will result in increased cure rates. Furthermore, the lack of overlapping side effects between abiraterone acetate and MDV3100 makes the possibility of combination therapy not only conceivable but quite attractive. Our deeper understanding of the pathways involved in the growth of prostate cancer and the multiple mechanisms that lead to the development of castration resistance certainly point to the use of combination therapies as the next cornerstone in the management of this heterogeneous and complex disease. 


\section{Acknowledgments}

The authors acknowledge the joint participation by Adrienne Helis Malvin Medical Research Foundation through its direct engagement in the continuous active conduct of medical research in conjunction with Baylor College of Medicine. This work was also supported by the Prostate Cancer Foundation (NM), the Conquer Cancer Foundation of the American Society of Clinical Oncology Young Investigator and Career Development Awards (both to NM), and a pilot/feasibility program of the Diabetes and Endocrinology Research Center (P30-DK079638) at Baylor College of Medicine (to NM). NM is a Dan L Duncan Scholar, a Caroline Wiess Law Scholar and a member of the Dan L Duncan Cancer Center (supported by the NCI Cancer Center Support Grant P30CA125123) at Baylor College of Medicine.

\section{Disclosure}

The authors report no conflicts of interest in this work.

\section{References}

1. Siegel R, Naishadham D, Jemal A. Cancer statistics, 2012. CA Cancer J Clin. 2012;62:10-29.

2. Huggins C, Hodges CV. Studies on prostatic cancer. I. The effect of castration, of estrogen and androgen injection on serum phosphatases in metastatic carcinoma of the prostate. Cancer Res. 1941;1: 293-297.

3. Chen Y, Clegg NJ, Scher HI. Anti-androgens and androgen-depleting therapies in prostate cancer: new agents for an established target. Lancet Oncol. 2009;10:981-991.

4. Holzbeierlein J, Lal P, LaTulippe E, et al. Gene expression analysis of human prostate carcinoma during hormonal therapy identifies androgenresponsive genes and mechanisms of therapy resistance. Am J Pathol. 2004; 164:217-227.

5. Attard G, Reid AH, A'Hern R, et al. Selective inhibition of CYP17 with abiraterone acetate is highly active in the treatment of castrationresistant prostate cancer. J Clin Oncol. 2009;27:3742-3748.

6. Scher HI, Sawyers CL. Biology of progressive, castration-resistant prostate cancer: directed therapies targeting the androgen-receptor signaling axis. J Clin Oncol. 2005;23:8253-8261.

7. Tannock IF, de Wit R, Berry WR, et al. Docetaxel plus prednisone or mitoxantrone plus prednisone for advanced prostate cancer. $N$ Engl J Med. 2004;351:1502-1512.

8. de Bono JS, Oudard S, Ozguroglu M, et al. Prednisone plus cabazitaxel or mitoxantrone for metastatic castration-resistant prostate cancer progressing after docetaxel treatment: a randomised open-label trial. Lancet. 2010;376:1147-1154.

9. Shapiro D, Tareen B. Current and emerging treatments in the management of castration-resistant prostate cancer. Expert Rev Anticancer Ther. 2012;12:951-964.

10. Lheureux S, Joly F. Cabazitaxel after docetaxel: a new option in metastatic castration-resistant prostate cancer. Bull Cancer. 2012;99:875880. French

11. Mostaghel EA, Page ST, Lin DW, et al. Intraprostatic androgens and androgen-regulated gene expression persist after testosterone suppression: therapeutic implications for castration-resistant prostate cancer. Cancer Res. 2007;67:5033-5041.
12. Chen Y, Sawyers CL, Scher HI. Targeting the androgen receptor pathway in prostate cancer. Curr Opin Pharmacol. 2008;8:440-448.

13. Scher HI, Buchanan G, Gerald W, Butler LM, Tilley WD. Targeting the androgen receptor: improving outcomes for castration-resistant prostate cancer. Endocr Relat Cancer. 2004;11:459-476.

14. Scher HI, Beer TM, Higano CS, et al. Antitumour activity of MDV3100 in castration-resistant prostate cancer: a phase 1-2 study. Lancet. 2010;375:1437-1446.

15. Scott HM, Mason JI, Sharpe RM. Steroidogenesis in the fetal testis and its susceptibility to disruption by exogenous compounds. Endocr Rev. 2009;30:883-925.

16. Payne AH, Hales DB. Overview of steroidogenic enzymes in the pathway from cholesterol to active steroid hormone. Endocr Rev. 2004;25:947-970.

17. Luu-The V, Bélanger A, Labrie F. Androgen biosynthetic pathways in the human prostate. Best Pract Res Clin Endocrinol Metab. 2008;22:207-221.

18. Hoivik EA, Lewis AE, Aumo L, Bakke M. Molecular aspects of steroidogenic factor 1 (SF-1). Mol Cell Endocrinol. 2010;315:27-39.

19. Lin L, Achermann JC. Steroidogenic factor-1 (SF-1, Ad4BP, NR5A1) and disorders of testis development. Sex Dev. 2008;2:200-209.

20. Aesøy R, Mellgren G, Morohashi K, Lund J. Activation of cAMPdependent protein kinase increases the protein level of steroidogenic factor-1. Endocrinology. 2002;143:295-303.

21. Schimmer BP, White PC. Minireview: steroidogenic factor 1: its roles in differentiation, development, and disease. Mol Endocrinol. 2010;24:1322-1337.

22. Penning TM, Byrns MC. Steroid hormone transforming aldo-keto reductases and cancer. Ann NY Acad Sci. 2009;1155:33-42.

23. Wilbert DM, Griffin JE, Wilson JD. Characterization of the cytosol androgen receptor of the human prostate. J Clin Endocrinol Metab. 1983;56:113-120.

24. Deslypere JP, Young M, Wilson JD, McPhaul MJ. Testosterone and 5 alpha-dihydrotestosterone interact differently with the androgen receptor to enhance transcription of the MMTVCAT reporter gene. Mol Cell Endocrinol. 1992;88:15-22.

25. Ohlson N, Wikström P, Stattin P, Bergh A. Cell proliferation and apoptosis in prostate tumors and adjacent non-malignant prostate tissue in patients at different time-points after castration treatment. Prostate. 2005;62:307-315.

26. Gregory CW, Johnson RT Jr, Mohler JL, French FS, Wilson EM. Androgen receptor stabilization in recurrent prostate cancer is associated with hypersensitivity to low androgen. Cancer Res. 2001;61:2892-2898.

27. Pfeiffer MJ, Smit FP, Sedelaar JP, Schalken JA. Steroidogenic enzymes and stem cell markers are upregulated during androgen deprivation in prostate cancer. Mol Med. 2011;17:657-664.

28. Mahajan NP, Liu Y, Majumder S, et al. Activated Cdc42-associated kinase Ack1 promotes prostate cancer progression via androgen receptor tyrosine phosphorylation. Proc Natl Acad Sci U S A. 2007;104:8438-8443.

29. Gregory CW, Whang YE, McCall W, et al. Heregulin-induced activation of HER2 and HER3 increases androgen receptor transactivation and CWR-R1 human recurrent prostate cancer cell growth. Clin Cancer Res. 2005;11:1704-1712.

30. Mellinghoff IK, Vivanco I, Kwon A, Tran C, Wongvipat J, Sawyers CL. HER2/neu kinase-dependent modulation of androgen receptor function through effects on DNA binding and stability. Cancer Cell. 2004;6:517-527.

31. Yeh S, Lin HK, Kang HY, Thin TH, Lin MF, Chang C. From HER2/ Neu signal cascade to androgen receptor and its coactivators: a novel pathway by induction of androgen target genes through MAP kinase in prostate cancer cells. Proc Natl Acad Sci U S A. 1999;96: 5458-5463.

32. Liu Y, Karaca M, Zhang Z, Gioeli D, Earp HS, Whang YE. Dasatinib inhibits site-specific tyrosine phosphorylation of androgen receptor by Ack1 and Src kinases. Oncogene. 2008;10:3208-3216. 
33. Asim M, Siddiqui IA, Hafeez BB, Baniahmad A, Mukhtar H. Src kinase potentiates androgen receptor transactivation function and invasion of androgen-independent prostate cancer C4-2 cells. Oncogene. 2008;27:3596-3604.

34. O’Malley BW, Kumar R. Nuclear receptor coregulators in cancer biology. Cancer Res. 2009;69:8217-8222.

35. Wu RC, Qin J, Yi P, Wong J, et al. Selective phosphorylations of the $\mathrm{SRC}-3 / \mathrm{AIB} 1$ coactivator integrate genomic responses to multiple cellular signaling pathways. Mol Cell. 2004;15:937-949.

36. Dehm SM, Schmidt LJ, Heemers HV, Vessella RL, Tindall DJ. Splicing of a novel androgen receptor exon generates a constitutively active androgen receptor that mediates prostate cancer therapy resistance. Cancer Res. 2008;68:5469-5477.

37. Hu R, Dunn TA, Wei S, et al. Ligand independent androgen receptor variants derived from splicing of cryptic exons signify hormonerefractory prostate cancer. Cancer Res. 2009;69:16-22.

38. Libertini SJ, Tepper CG, Rodriguez V, Asmuth DM, Kung HJ, Mudryj M. Evidence for calpain-mediated androgen receptor cleavage as a mechanism for androgen independence. Cancer Res. 2007;67:9001-9005.

39. Harada N, Inoue K, Yamaji R, Nakano Y, Inui H. Androgen deprivation causes truncation of the $\mathrm{C}$-terminal region of androgen receptor in human prostate cancer LNCaP cells. Cancer Sci. 2012;103:1022-1027.

40. Tran C, Ouk S, Clegg NJ, et al. Development of a second-generation antiandrogen for treatment of advanced prostate cancer. Science. 2009;324:787-790.

41. Mitsiades N, Chen Y, Scher HI. The AR axis as a pathogenetic mechanism and therapeutic target throughout the clinical states of prostate cancer: opportunities for second-line hormonal manipulations in castration-resistant prostate cancer. In: Scardino PT, Linehan WM, Zelefsky MJ, Vogelzang NJ. Comprehensive Textbook of Genitourinary Oncology, 4th ed. Baltimore: Lippincott Williams \& Wilkins; 2011:262-273.

42. Mitsiades N, Sung CC, Schultz N, et al. Distinct Patterns of Dysregulated Expression of Enzymes Involved in Androgen Synthesis and Metabolism in Metastatic Prostate Cancer Tumors. Cancer Res. 2012;72(23):6142-6152.

43. Waltering KK, Helenius MA, Sahu B, et al. Increased expression of androgen receptor sensitizes prostate cancer cells to low levels of androgens. Cancer Res. 2009;69:8141-8149.

44. Chen CD, Welsbie DS, Tran C, et al. Molecular determinants of resistance to antiandrogen therapy. Nat Med. 2004;10:33-39.

45. Kelly WK, Scher HI. Prostate specific antigen decline after antiandrogen withdrawal: the flutamide withdrawal syndrome. J Urol. 1993;149:607-609.

46. Klotz L. Maximal androgen blockade for advanced prostate cancer. Best Pract Res Clin Endocrinol Metab. 2008;22:331-340.

47. Pousette A, Carlström K, Stege R. Androgens during different modes of endocrine treatment of prostatic cancer. Urol Res. 1989;17:95-98.

48. Eri LM, Haug E, Tveter KJ. Effects on the endocrine system of longterm treatment with the luteinizing hormone-releasing hormone agonist leuprolide in patients with benign prostatic hyperplasia. Scand J Clin Lab Invest. 1996;56:319-325.

49. Locke JA, Guns ES, Lubik AA, et al. Androgen levels increase by intratumoral de novo steroidogenesis during progression of castrationresistant prostate cancer. Cancer Res. 2008;68:6407-6415.

50. Page ST, Lin DW, Mostaghel EA, et al. Persistent intraprostatic androgen concentrations after medical castration in healthy men. J Clin Endocrinol Metab. 2006;91:3850-3856

51. Nishiyama T, Hashimoto Y, Takahashi K. The influence of androgen deprivation therapy on dihydrotestosterone levels in the prostatic tissue of patients with prostate cancer. Clin Cancer Res. 2004;10: 7121-7126.

52. Montgomery RB, Mostaghel EA, Vessella R, et al. Maintenance of intratumoral androgens in metastatic prostate cancer: a mechanism for castration-resistant tumor growth. Cancer Res. 2008;68:4447-4454.
53. Geller J, Albert JD, Nachtsheim DA, Loza D. Comparison of prostatic cancer tissue dihydrotestosterone levels at the time of relapse following orchiectomy or estrogen therapy. J Urol. 1984;132: 693-696.

54. Mohler JL, Gregory CW, Ford $\mathrm{OH} 3 \mathrm{rd}$, et al. The androgen axis in recurrent prostate cancer. Clin Cancer Res. 2004;10:440-448.

55. Mitsiades N, Schultz N, Taylor BS, et al. Increased expression of androgen receptor (AR) and enzymes involved in androgen synthesis in metastatic prostate cancer: targets for novel personalized therapies. J Clin Oncol. 2009;27:5002.

56. Stanbrough M, Bubley GJ, Ross K, et al. Increased expression of genes converting adrenal androgens to testosterone in androgen-independent prostate cancer. Cancer Res. 2006;66:2815-2825.

57. Hofland J, van Weerden WM, Dits NF, et al. Evidence of limited contributions for intratumoral steroidogenesis in prostate cancer. Cancer Res. 2010;70:1256-1264.

58. Pelletier G. Expression of steroidogenic enzymes and sex-steroid receptors in human prostate. Best Pract Res Clin Endocrinol Metab. 2008;22:223-228.

59. Mostaghel EA, Nelson PS. Intracrine androgen metabolism in prostate cancer progression: mechanisms of castration resistance and therapeutic implications. Best Pract Res Clin Endocrinol Metab. 2008;22:243-258.

60. Ryan CJ, Halabi S, Ou SS, Vogelzang NJ, Kantoff P, Small EJ. Adrenal androgen levels as predictors of outcome in prostate cancer patients treated with ketoconazole plus antiandrogen withdrawal: results from a cancer and leukemia group B study. Clin Cancer Res. 2007; 13:2030-2037.

61. Oh W. Secondary hormonal therapies in the treatment of prostate cancer. Urology. 2002;60 Suppl 3:87-92.

62. Rowlands MG, Barrie SE, Chan F, et al. Esters of 3-pyridylacetic acid that combine potent inhibition of 17 alpha-hydroxylase/C17,20-lyase (cytochrome P450-417alpha) with resistance to esterase hydrolysis. J Med Chem. 1995;38:4191-4197.

63. Food and Drug Administration. Zytiga prescribing information. 2012. Available from: http://www.accessdata.fda.gov/drugsatfda_docs/ label/2012/202379s004 lbl.pdf. Accessed November 27, 2012.

64. Attard G, Belldegrun AS, de Bono JS. Selective blockade of androgenic steroid synthesis by novel lyase inhibitors as a therapeutic strategy for treating metastatic prostate cancer. BJU Int. 2005;96: 1241-1246.

65. O'Donnell A, Judson I, Dowsett M, et al. Hormonal impact of the 17-hydroxylase/C17,20-lyase inhibitor abiraterone acetate (CB7630) in patients with prostate cancer. Br J Cancer. 2004;90:2317-2325.

66. Attard G, Reid AH, Yap TA, et al. Phase I clinical trial of a selective inhibitor of CYP17, abiraterone acetate, confirms that castrationresistant prostate cancer commonly remains hormone driven. $\mathrm{J}$ Clin Oncol. 2008;26:4563-4571.

67. Attard G, Reid AH, Auchus RJ, et al. Clinical and biochemical consequences of CYP17A1 inhibition with abiraterone given with and without exogenous glucocorticoids in castrate men with advanced prostate cancer. J Clin Endocrinol Metab. 2012;97:507-516.

68. Danila DC, Morris MJ, de Bono JS, et al. Phase II multicenter study of abiraterone acetate plus prednisone therapy in patients with docetaxeltreated castration-resistant prostate cancer. J Clin Oncol. 2010;28: 1496-1501.

69. Ryan CJ, Smith MR, Fong L, et al. Phase I clinical trial of the CYP17 inhibitor abiraterone acetate demonstrating clinical activity in patients with castration-resistant prostate cancer who received prior ketoconazole therapy. J Clin Oncol. 2010;28:1481-1488.

70. de Bono JS, Logothetis CJ, Molina A, et al. Abiraterone and increased survival in metastatic prostate cancer. N Engl J Med. 2011;364:1995-2005.

71. Ryan CJ, Smith MR, de Bono JS, et al Interim analysis (IA) results of COU-AA-302, a randomized, phase III study of abiraterone acetate (AA) in chemotherapy-naive patients (pts) with metastatic castrationresistant prostate cancer (mCRPC). J Clin Oncol. 2012;30:LBA4518. 
72. Taplin M, Montgomery RB, Logothetis C, et al. Effect of neoadjuvant abiraterone acetate (AA) plus leuprolide acetate (LHRHa) on PSA, pathological complete response (pCR), and near pCR in localized high-risk prostate cancer (LHRPC): Results of a randomized phase II study. J Clin Oncol. 2012;30:4521.

73. Efstathiou E, Davis JW, Troncoso P, et al. Cytoreduction and androgen signaling modulation by abiraterone acetate (AA) plus leuprolide acetate (LHRHa) versus LHRHa in localized high-risk prostate cancer (PCa): preliminary results of a randomized preoperative study. J Clin Oncol. 2012;30:4556

74. Petrylak DP, Gandhi JG, Clark WR, et al. Phase I results from a phase I/II study of orteronel, an oral, investigational, nonsteroidal 17,20-lyase inhibitor, with docetaxel and prednisone (DP) in metastatic castrationresistant prostate cancer (mCRPC). J Clin Oncol. 2012;30:4656.

75. Dreicer R, Agus DB, Bellmunt J, et al. A phase III, randomized, doubleblind, multicenter trial comparing the investigational agent orteronel (TAK-700) plus prednisone (P) with placebo plus $\mathrm{P}$ in patients with metastatic castration-resistant prostate cancer (mCRPC) that has progressed during or following docetaxel-based therapy. J Clin Oncol. 2012;30:TPS4693.
76. Sun S, Sprenger CC, Vessella RL, et al. Castration resistance in human prostate cancer is conferred by a frequently occurring androgen receptor splice variant. J Clin Invest. 2010;120:2715-2730.

77. Hörnberg E, Ylitalo EB, Crnalic S, et al. Expression of androgen receptor splice variants in prostate cancer bone metastases is associated with castration-resistance and short survival. PLoS One. 2011;6:e19059.

78. Mostaghel EA, Marck BT, Plymate SR, et al. Resistance to CYP17A1 inhibition with abiraterone in castration-resistant prostate cancer: induction of steroidogenesis and androgen receptor splice variants. Clin Cancer Res. 2011;17:5913-5925.

79. Cai C, Chen S, Ng P, et al. Intratumoral de novo steroid synthesis activates androgen receptor in castration-resistant prostate cancer and is upregulated by treatment with CYP17A1 inhibitors. Cancer Res. 2011;71:6503-6513.

80. Scher HI, Fizazi K, Saad F, et al. Increased survival with enzalutamide in prostate cancer after chemotherapy. $N$ Engl J Med. 2012; 367:1187-1197.
OncoTargets and Therapy

\section{Publish your work in this journal}

OncoTargets and Therapy is an international, peer-reviewed, open access journal focusing on the pathological basis of all cancers, potential targets for therapy and treatment protocols employed to improve the management of cancer patients. The journal also focuses on the impact of management programs and new therapeutic agents and protocols on

\section{Dovepress}

patient perspectives such as quality of life, adherence and satisfaction. The manuscript management system is completely online and includes a very quick and fair peer-review system, which is all easy to use. Visit http://www.dovepress.com/testimonials.php to read real quotes from published authors. 